(2) Open Access Full Text Article

ORIGINAL RESEARCH

\title{
Assessment of the Effect of Metabolic Syndrome on the Autophagy Marker LC3 in Psoriasis Vulgaris Patients: A Cross-Sectional Study
}

This article was published in the following Dove Press journal: Clinical, Cosmetic and Investigational Dermatology

\author{
Essam A Nada' \\ Eman MS Muhammad (iD) ${ }^{2}$ \\ Sheren FM Ahmed (iD ${ }^{2}$ \\ Asmaa MS Tamam ' \\ Amr Abdelhamed (iD) \\ 'Dermatology, Venereology and \\ Andrology Department, Faculty of \\ Medicine, Sohag University, Sohag, Egypt; \\ ${ }^{2}$ Pathology Department, Faculty of \\ Medicine, Sohag University, Sohag, Egypt
}

Purpose: Psoriasis vulgaris, one of the most prevalent chronic inflammatory skin diseases, is associated with metabolic syndrome (MetS). Autophagy, an intracellular degradation system is essential for cell survival and differentiation, and its dysfunction may contribute to metabolic diseases. A cross-sectional study was conducted on 38 psoriasis vulgaris patients and 16 healthy control subjects to 1) Assess immunohistochemical (IHC) expression of microtubule-associated protein light chain 3 (LC3); 2) Evaluate the relationship between Psoriasis Area Severity Index (PASI) score, and LC3 expression.

Patients and Methods: PASI score was evaluated for all psoriasis patients. Lipid profile, blood sugar, and CRP were done for all patients and controls. A punch biopsy was taken from lesional and perilesional skin of psoriasis patients and normal skin of the controls. Tissue sections were prepared. IHC LC3 staining was done and evaluated.

Results: LC3 was nearly absent, in the epidermis of the lesional skin of psoriasis while it was strong among control $(\mathrm{p}=0.001)$. LC3 expression in the lesional skin of psoriasis vulgaris was lower than its expression in perilesional $(p=0.001)$. However, LC3 expression was not significantly changed with PASI or the presence/absence of MetS.

Conclusion: A potential link between psoriasis vulgaris and autophagy as assessed by LC3 could be present. LC3 was down-regulated in psoriasis lesions than in normal skin. However, its expression did not change with PASI or MetS. An autophagy enhancer might be used as a possible therapeutic target in psoriasis vulgaris patients.

Keywords: psoriasis vulgaris, Psoriasis Area Severity Index score, PASI score, metabolic syndrome, autophagy, microtubule-associated protein light chain 3, LC3

\section{Introduction}

Psoriasis vulgaris is a common chronic recurrent inflammatory skin disease with a strong genetic predisposition, ${ }^{1}$ affecting $2 \%$ of the general population. It has a multifactorial etiology including genetic, epigenetic, and environmental factors, leading to keratinocyte proliferation and immune cell infiltration, mostly T cell. ${ }^{2}$ An association between psoriasis and metabolic diseases such as obesity, diabetes, and cardiovascular diseases (CVDs) has been recognized. ${ }^{3}$ The prevalence of MetS increases in psoriasis patients, ${ }^{4}$ and the severity (PASI score) and duration of psoriasis are positively correlated with the prevalence of MetS and its components. ${ }^{3}$

Autophagy is an intracellular process by which a part of the cytoplasm is degraded through the lysosomes. It is important for cell survival and differentiation. Autophagy dysfunction may be an important contributor to metabolic diseases such
Correspondence: Amr Abdelhamed Department of Dermatology,

Venereology, and Andrology, Faculty of

Medicine, Sohag University, Sohag 82524,

Egypt

Tel +20 1005825574

Email dramr80@yahoo.com 
as diabetes, obesity, and MetS. ${ }^{5}$ Defects in autophagy may lead to inflammation and keratinocyte proliferation, which are the two main pathological features of psoriasis. ${ }^{6}$ However, no previous study investigates tissue autophagy in psoriasis patients with MetS.

One of the most specific markers of autophagy monitoring is LC $3{ }^{7}$ In normal skin, LC3 is expressed in all epidermal layers with the strongest expression in the granular cell layer. ${ }^{8}$ In keratinocyte, immunofluorescence analysis showed perinuclear localization of LC $3 .{ }^{9} \mathrm{LC} 3$ expression is reduced or absent in the epidermis of psoriasis patients. ${ }^{8}$ Moreover, the ATG16L1 (2q37) gene which is responsible for the formation of the ATG16L1 protein that is a key protein in the autophagy pathway, and polymorphisms in this gene have been associated with the development of psoriasis. ${ }^{10}$

Therefore, this study aimed to assess immunohistochemistry (IHC) expression of LC3 in the skin of psoriasis vulgaris patients compared with that in the controls; and to evaluate the relationship between autophagy as assessed by LC3 expression, MetS and psoriasis vulgaris severity evaluated by PASI score.

\section{Materials and Methods}

The study included 38 patients of psoriasis vulgaris and 16 healthy individuals (control) who were attending the Dermatology Outpatient Clinic of Sohag University Hospitals, Sohag, Egypt; from November 2017 to April 2019. Sample size was determined from the previous studies in the literature that reported the prevalence of MetS varies between $24 \%$ and $60 \%$ in psoriasis vulgaris patients. The study was approved by the Research and Ethical Committee of Sohag Faculty of Medicine. A written informed consent was obtained from all participants. The study was conducted in accordance with the Declaration of Helsinki. The diagnosis of psoriasis was established according to the clinical findings and confirmed by routine H\&E stained biopsy sections.

\section{Inclusion Criteria}

Only patients with typical clinical findings of psoriasis vulgaris (diagnosis of psoriasis duration $\geq 6$ months) and aged 18 years or more were included in the study.

\section{Exclusion Criteria}

Patients with other clinical varieties of psoriasis, patients receiving topical/systemic treatment for 1 month before enrollment, pregnant or lactating women, and patients with advanced hepatic or renal failure were excluded.
All participants were subjected to:

1. Initial evaluation:

The general examination included weight, height, body mass index (BMI), blood pressure, and waist circumference (WC) which was measured immediately below the lowest ribs. ${ }^{11}$

\section{Dermatological evaluation:}

The Psoriasis Area Severity Index (PASI) was used for patients' evaluation. ${ }^{12}$ It is a measure of the average redness, thickness, and scaliness of the lesions (each graded on a $0-4$ scale), weighted by the area of involvement. The net result of PASI ranges from 0 to 72 . The severity of plaque psoriasis was graded as mild $(\mathrm{PASI} \leq 10)$ and moderate to severe $(>10){ }^{13}$

\section{Laboratory investigations:}

3-1. Fasting blood glucose level.

3-2. Lipid profile assessment: Blood samples were taken after overnight fasting (12-14 hrs) to assess triglyceride (TGs), total cholesterol, high-density lipoprotein (HDL), and low-density lipoprotein (LDL).

3-3. C-reactive protein (CRP) and serum uric acid: as markers of chronic inflammation.

4. Metabolic syndrome diagnosis:

Diagnosis of MetS was done using the Joint Interim Statement (JIS), ${ }^{14}$ with Egyptian cutoffs ${ }^{15}$ as any three of the following: elevated $\mathrm{WC}>100.5 \mathrm{~cm}$ in men and > $96.25 \mathrm{~cm}$ in women; TGs $150 \mathrm{mg} / \mathrm{dl}$ or greater; HDL cholesterol $<40 \mathrm{mg} / \mathrm{dl}$ in men and $<50 \mathrm{mg} / \mathrm{dl}$ in women; blood pressure $\geq 130 / 85 \mathrm{mmHg}$; and fasting glucose $\geq$ $100 \mathrm{mg} / \mathrm{dl}$.

\section{Skin biopsy:}

Four mm punch biopsy was obtained from lesional and non-lesional skin of psoriasis patients, and normal skin of control individuals. Biopsies were fixed in $10 \%$ neutral formalin and paraffin-embedded serial sections were prepared.

\section{5-1. Hematoxylin and Eosin (H\&E) staining:}


- Sections of $4 \mu \mathrm{m}$ thick from formalin-fixed paraffin-embedded tissue blocks were used for $H \& E$ staining.

\section{5-2. LC3 IHC staining:}

- Sections of $4 \mu \mathrm{m}$ thick were cut and mounted on saline-coated glass slides and the slides were incubated overnight at room temperature for accurate adhesion of the tissues to the slides. The slides were de-paraffinized in xylene for 20 mins, rehydrated in down-regulated alcohol, then rinsed in distilled water. Endogenous peroxidase activity was blocked by incubation of tissue sections in $0.6 \%$ hydrogen peroxide for $10 \mathrm{mins}$.

- The tissue sections were washed twice in diluted phosphate-buffered saline (PBS), then antigens were retrieved by boiling the sections twice in citrate buffer, $\mathrm{pH} 6.0$ using a microwave at mid-high power for 10 mins each, followed by cooling down to room temperature for 30 mins. After washing twice in PBS, tissue sections were treated with superblock. Tissue sections were rinsed twice with PBS and incubated with rabbit anti LC3B monoclonal antibody (D11, XP® \#3868T, Cell Signaling Technology) at a concentration of 1:3200 for overnight at room temperature.

- Excess reagent was thrown off and tissue sections were rinsed twice in PBS, incubated with streptavidin for 10 mins at room temperature, washed twice in PBS, and exposed to a freshly prepared 3,3'diaminobenzidine tetrahydrochloride solution (DAB) for 5-10 mins to yield an insoluble brown deposit (Chromogen detection system was purchased from Dako). Finally, the sections were counterstained with hematoxylin.

- Sections from astrocytoma were used as a positive control.

- LC3-IHC expression was analyzed independently of the clinico-pathological data. The analysis was done with two blind pathologists.

5-3. Analysis of LC3:

- The immune-reactive score (IRS) was determined by multiplying an estimate of staining quantity which is the percentage of the immune-reactive cells with an estimate of the staining intensity. ${ }^{16}$ Staining quantity is scored as follows: no staining $=0$; positive staining in $\leq 25 \%$ of cells counted $=1$; positive in $>25 \%$ and $\leq 50 \%=2$; positive in $>50 \%$ and $\leq 75 \%=3$; positive in $>75 \%=4$. Staining intensity is scored on a scale of $0-3$ where: no staining $=0$; weak $=1$; moderate $=2$; strong $=3$. An IRS of 0 was considered negative; $1-4$ was considered weak; 6-8 was moderate, and 9-12 was considered strong.

\section{Statistical Analysis}

Data were analyzed using Statistical Package for the Social Sciences (SPSS) software (version 22). Quantitative variables were presented as mean \pm standard deviation (SD) when results were normally distributed and as median (interquartile range $25^{\text {th }}-75^{\text {th }}$ ) when results were not normally distributed. Categorical variables were expressed as percentages. For continuous variables, a comparison between two normally distributed variables independent samples' $t$-test was used, while the MannWhitney $U$-test was used to compare between two not normally distributed variables. Kruskal-Wallis test was used for comparison between more than 2 groups. For categorical variables, the Chi-square test was used. P-value $\leq 0.05$ was considered significant.

\section{Results}

The current study was conducted on 54 participants (38 patients with psoriasis vulgaris and 16 healthy controls). Patients were mainly males; $27 / 38$ (71.1\%) with a mean age \pm SD was $48.45 \pm 14.94$ years. According to the PASI score, $19 / 38(50 \%)$ of patients had mild psoriasis $(\leq 10)$. The mean duration of psoriasis was $7.2 \pm 5.2$ years. In comparison between patients and control as regard components of MetS, there was a statistically significant difference in systolic blood pressure $(p<0.001)$, diastolic blood pressure $(\mathrm{p}=0.036)$ being higher in patients, and HDL $(p=<0.001)$ being lower in patients as compared to control. Other demographic data are shown in Table 1.

MetS diagnosis was significantly higher in patients 16 / $38(42.1 \%)$ as compared to control $4 / 16(25 \%)(p=0.003)$. Patients had significantly higher WC $(\mathrm{p}=0.002)$, lower HDL $(p=0.0004)$, and increased TGs $(p=0.04)$ compared to control. Other data are shown in Table 2.

H\&E stained tissue sections from perilesional and lesional psoriatic skin from the patients and normal skin from the control group were examined and LC3 expression was assessed using IHC staining as shown in Figure 1. A significantly higher expression LC3 expression was found in the skin of the control group (IRS was 12.0 and the range was $6.0-12.0$ ) than in perilesional, (IRS was 1.5 
Table I Demographic Data of Psoriasis Vulgaris Patients and Control

\begin{tabular}{|c|c|c|c|}
\hline & $\begin{array}{l}\text { Psoriasis } \\
\text { Patients } \\
(n=38)\end{array}$ & $\begin{array}{l}\text { Control } \\
(n=16)\end{array}$ & $P$ value \\
\hline & $\begin{array}{l}\text { Mean } \pm \text { SD } \\
\text { Median }\left(25^{\text {th }}-\right. \\
\left.75^{\text {th }}\right) n(\%)\end{array}$ & $\begin{array}{l}\text { Mean } \pm \text { SD } \\
\text { Median }\left(25^{\text {th }}-\right. \\
\left.75^{\text {th }}\right) n(\%)\end{array}$ & \\
\hline \multicolumn{4}{|l|}{ History: } \\
\hline Age & $48.45 \pm 14.94$ & $45.38 \pm 14.04$ & 0.486 \\
\hline \multicolumn{4}{|l|}{ Sex: } \\
\hline $\begin{array}{ll}\text { - } & \text { Male } \\
\text { - } & \text { Female }\end{array}$ & $\begin{array}{l}27(71.1 \%) \\
11(28.9 \%)\end{array}$ & $\begin{array}{l}8(50.0 \%) \\
8(50.0 \%)\end{array}$ & 0.122 \\
\hline \multicolumn{4}{|l|}{ Residence: } \\
\hline $\begin{array}{l}\text { - Rural } \\
\text { - Sub-urban } \\
\text { - Urban }\end{array}$ & $\begin{array}{l}29(76.3 \%) \\
4(10.5 \%) \\
5(13.2 \%)\end{array}$ & $\begin{array}{l}13(81.3 \%) \\
2(12.5 \%) \\
\text { I (6.3\%) }\end{array}$ & 0.756 \\
\hline \multicolumn{4}{|l|}{ Occupation: } \\
\hline $\begin{array}{l}\text { - } \text { Not working } \\
\text { - Employee } \\
\text { - Farmer } \\
\text { - Worker }\end{array}$ & $\begin{array}{l}15(39.5 \%) \\
6(15.8 \%) \\
3(7.9 \%) \\
14(36.8 \%)\end{array}$ & $\begin{array}{l}8(50.0 \%) \\
2(12.5 \%) \\
3(18.8 \%) \\
3(18.8 \%)\end{array}$ & 0.433 \\
\hline \multicolumn{4}{|l|}{ Marital status: } \\
\hline $\begin{array}{ll}\text { - } & \text { Single } \\
\text { - } & \text { Married } \\
\text { - Widow }\end{array}$ & $\begin{array}{l}\text { I (2.6\%) } \\
35(92.1 \%) \\
2(5.3 \%)\end{array}$ & $\begin{array}{l}0(0 \%) \\
16(100.0 \%) \\
0(0 \%)\end{array}$ & 0.512 \\
\hline \multicolumn{4}{|l|}{ Special habits: } \\
\hline $\begin{array}{l}\text { - } \text { No } \\
\text { - Cigarette } \\
\text { - Shisha } \\
\text { - } \text { Mixed (Cigarette } \\
\text { + shisha) }\end{array}$ & $\begin{array}{l}21(55.3 \%) \\
8(21.1 \%) \\
5(13.2 \%) \\
4(10.5 \%)\end{array}$ & $\begin{array}{l}\text { II (68.8\%) } \\
2(12.5 \%) \\
2(12.5 \%) \\
\text { I (6.3\%) }\end{array}$ & 0.797 \\
\hline $\begin{array}{l}\text { Smoking Brinkman } \\
\text { index }\end{array}$ & $515 \pm 336$ & $460 \pm 120$ & 0.882 \\
\hline \multicolumn{4}{|l|}{ Examination: } \\
\hline $\begin{array}{l}\text { Weight }(\mathrm{kg}) \\
\text { Height }(\mathrm{cm}) \\
\text { BMI } \\
\text { WC }(\mathrm{cm}) \\
\text { Systolic blood } \\
\text { pressure }\end{array}$ & $\begin{array}{l}76.08 \pm \mid 5.58 \\
|66.95 \pm 8.0| \\
27.2 \mid \pm 4.73 \\
100.97 \pm \mid 5.62 \\
\mid 25.53 \\
(|05.89-| 30)\end{array}$ & $\begin{array}{l}73.63 \pm 9.76 \\
165.19 \pm 8.44 \\
26.76 \pm 4.28 \\
92.69 \pm 10.27 \\
110.63 \\
(99.98-115)\end{array}$ & $\begin{array}{l}0.563 \\
0.47 \mid \\
0742 \\
0.057 \\
<0.00 I^{*}\end{array}$ \\
\hline $\begin{array}{l}\text { Diastolic blood } \\
\text { pressure }\end{array}$ & $\begin{array}{l}79.08 \\
(72.29-85)\end{array}$ & $\begin{array}{l}73.13 \\
(70.04-79)\end{array}$ & $0.036 *$ \\
\hline
\end{tabular}

(Continued)
Table I (Continued).

\begin{tabular}{|c|c|c|c|}
\hline & $\begin{array}{l}\text { Psoriasis } \\
\text { Patients } \\
(n=38)\end{array}$ & $\begin{array}{l}\text { Control } \\
(n=16)\end{array}$ & $P$ value \\
\hline & $\begin{array}{l}\text { Mean } \pm \text { SD } \\
\text { Median }\left(25^{\text {th }}-\right. \\
\left.75^{\text {th }}\right) \text { n (\%) }\end{array}$ & $\begin{array}{l}\text { Mean } \pm \text { SD } \\
\text { Median }\left(25^{\text {th }}-\right. \\
\left.75^{\text {th }}\right) n(\%)\end{array}$ & \\
\hline $\mathrm{HDL}$ & $33.81 \pm 10.16$ & $44.44 \pm 8.04$ & $<0.001 *$ \\
\hline TGs & $\begin{array}{l}167.29 \\
(|4| .26-182.5)\end{array}$ & $\begin{array}{l}\mid 42.63 \\
(66.74-\mid 57.5)\end{array}$ & 0.615 \\
\hline FBG & $\begin{array}{l}91.97 \\
(30.63-95)\end{array}$ & $\begin{array}{l}\text { III.38 } \\
(75.15-105.5)\end{array}$ & 0.649 \\
\hline Serum UA & $1.58(0.5-2)$ & $1.75(0.45-2)$ & 0.076 \\
\hline CRP & $3.5(3-6)$ & $4(4-6)$ & 0.984 \\
\hline
\end{tabular}

Note: *Statistically significant difference $p<0.05$.

Abbreviations: BMI, body mass index; WC, waist circumference; HDL, highdensity lipoprotein; TGs, triglycerides; FBG, fasting blood glucose; UA, uric acid; CRP, $C$ reactive protein.

and the range was 1.0-2.0) and lesional (IRS was 0.0 and the range was 0.0-1.0) skin of patients as shown in Figure 2.

LC3 expression was significantly increased in the skin of the control group without MetS than in the skin of the control with MetS (IRS was 12 and 9 and the range was 6.75-12 and 3.75-12, respectively; $p=0.003$ ). However, there was no significant variation in lesional expression of LC3 between patients with MetS and patients without MetS (IRS was 0 and the range was 0.0-2.0 for each of them) as shown in Figure 3.

Besides, no significant statistical difference in LC3 expression comparing in lesional skin of mild psoriasis

Table 2 Frequencies and Percentage of Different Criteria of MetS Among Patients and Control

\begin{tabular}{|c|c|c|c|}
\hline & $\begin{array}{l}\text { Psoriasis } \\
\text { Patients } \\
(n=38)\end{array}$ & $\begin{array}{l}\text { Control } \\
(n=16)\end{array}$ & $P$ value \\
\hline $\begin{array}{l}\text { WC }>100.5 \text { (male) or }> \\
96.25 \text { (female) }\end{array}$ & $20(52.63 \%)$ & $4(25 \%)$ & $0.002^{*}$ \\
\hline $\begin{array}{l}\text { Systolic blood } \\
\text { pressure } \geq 130\end{array}$ & $13(34.21 \%)$ & 5 (31.25\%) & 0.09 \\
\hline $\begin{array}{l}\text { Diastolic blood } \\
\text { pressure } \geq 85\end{array}$ & II (28.94\%) & $4(25 \%)$ & 0.121 \\
\hline $\begin{array}{l}\text { HDL }<40 \text { (male) or }<50 \\
\text { (female) }\end{array}$ & 31 (81.57\%) & $8(50 \%)$ & $0.0004 *$ \\
\hline TGs $\geq 150$ & 17 (44.73\%) & 6 (37.5\%) & $0.04 *$ \\
\hline FBG $\geq 100$ & 8 (21.05\%) & $4(25 \%)$ & 0.386 \\
\hline Diagnosis of MetS & $16(42.1 \%)$ & $4(25 \%)$ & $0.003^{*}$ \\
\hline
\end{tabular}

Note: *Statistically significant difference $p<0.05$.

Abbreviations: WC, waist circumference; HDL, high-density lipoprotein; TGs, triglycerides; FBG, fasting blood glucose; MetS, metabolic syndrome. 

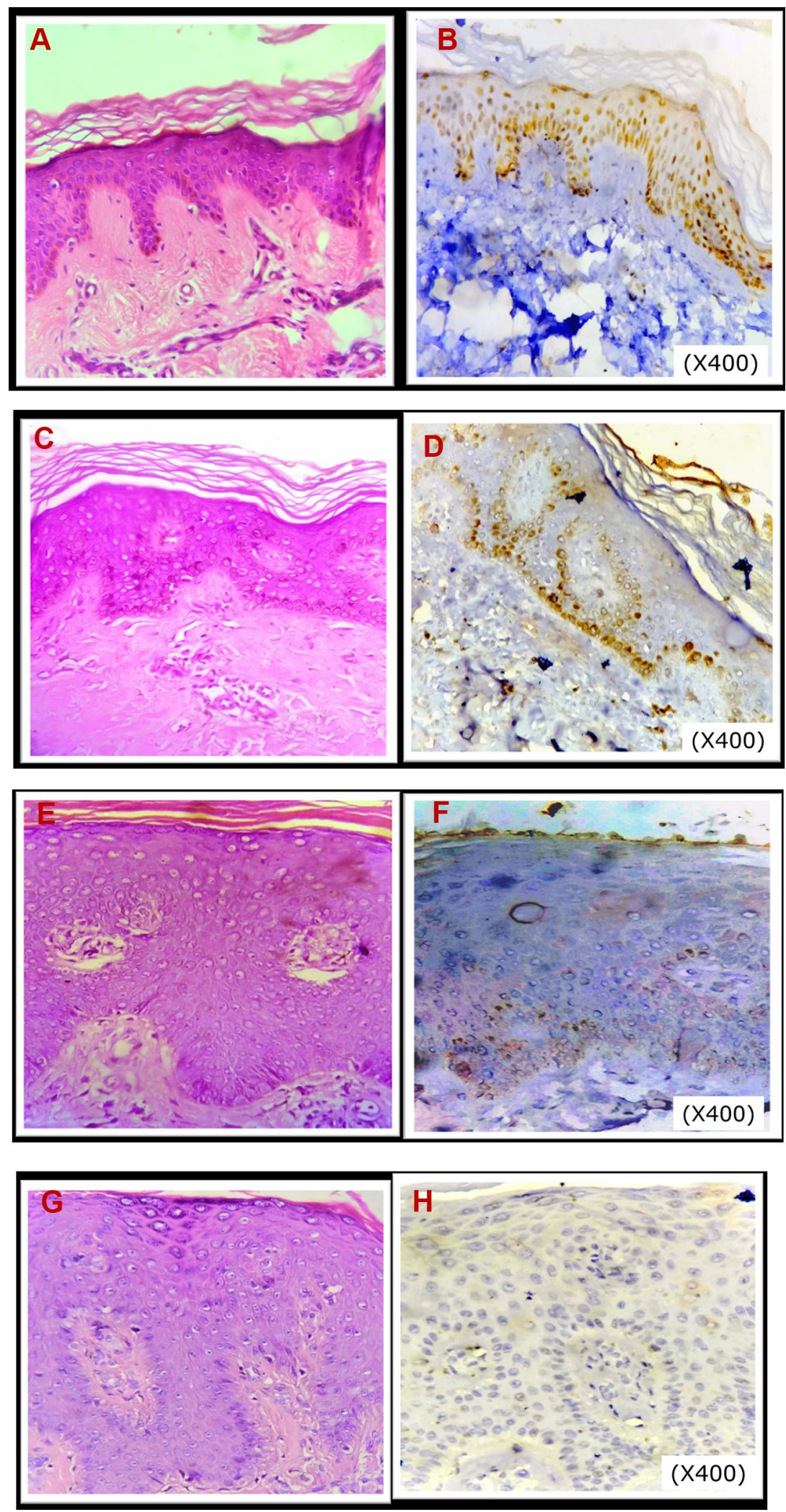

Figure I (A) Normal skin of control (H\&E); (B) Normal skin of control showing strong expression of LC3; (C) Normally-looking perilesional skin (H\&E); (D) Moderate expression of LC3 in perilesional skin; (E) Psoriatic lesional skin (H\&E); (F) Psoriatic lesional skin with weak expression of LC3; (G) Psoriatic lesional skin (H\&E); (H) Negative expression of LC3 in psoriatic lesional skin (x400). 


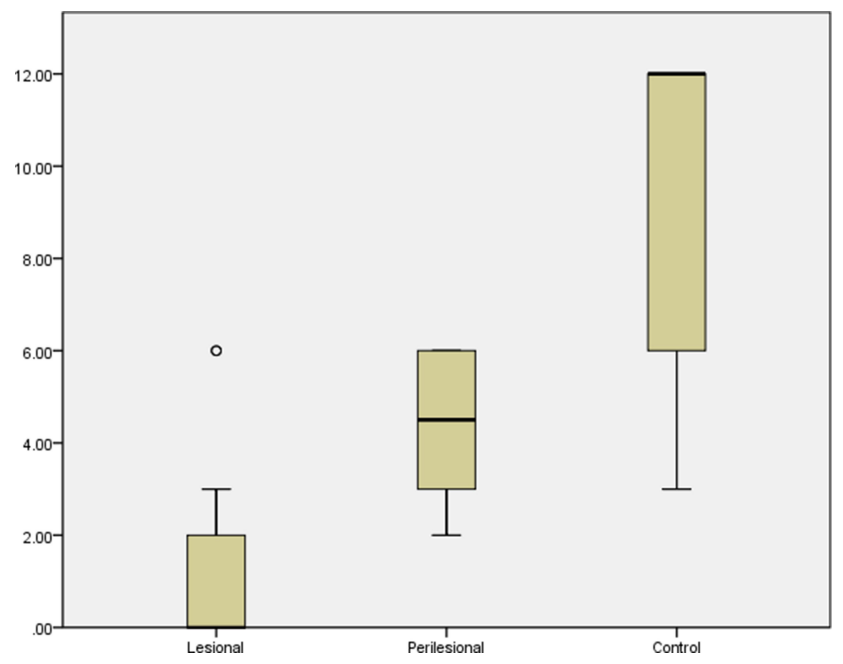

Figure 2 Expression of staining quality of LC3 by IHC in patients and control.

and that of moderate to severe psoriasis patients (IRS was 0 and the range was $0.0-2.0$ for each of them) as shown in Figure 4.

\section{Discussion}

Psoriasis is considered not only a skin disease but also it is associated with several comorbidities such as MetS components. This association could be due to shared genetic factors and chronic inflammatory pathways between psoriasis and MetS. ${ }^{17}$ Autophagy study has been growing in skin diseases including psoriasis. ${ }^{18}$ In the same context, autophagy has a growing contribution to MetS pathogenesis. $^{19}$

In the current study, LC3 expression was nearly absent, in the epidermis of lesional skin of psoriasis vulgaris patients while it was strong among the control group.

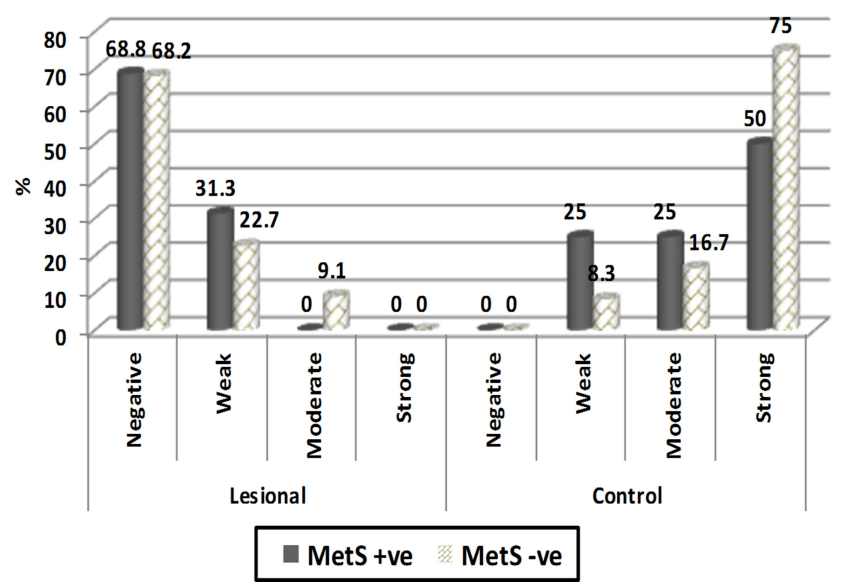

Figure 3 Expression of staining intensity of LC3 by IHC in lesional psoriasis with and without MetS and control with and without MetS.

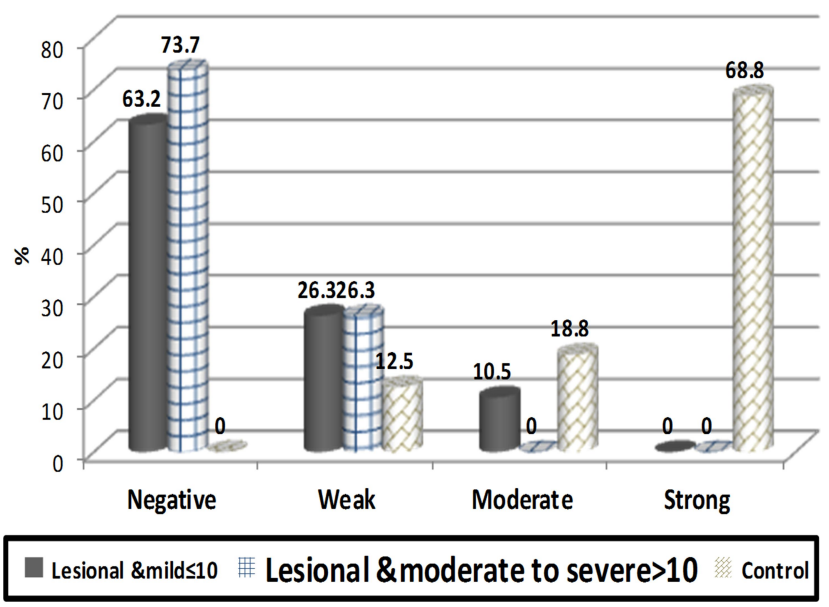

Figure 4 Expression of staining intensity of LC3 by IHC in lesional mild psoriasis patients (PASI $\leq 10)$, lesional psoriasis moderate to severe patients (PASI>I0) and the control group.

These results matched with a study that investigated the expression pattern of several autophagy markers (LC3, ULK1, BECN1, and ATG5-ATG12) in the skin of six psoriasis patients compared with the skin of five healthy volunteers. In lesional skin, LC3 expression was absent while ULK1 expression was increased in the whole epidermis except the parakeratotic layer, and BECN1 and ATG5-ATG12 expressions were increased in the suprabasal layer of the epidermis. ${ }^{9}$ Also, another study reported decreased LC3I and LC3II expression in lesional psoriatic skin compared to control, and this was accompanied by an increased expression of p62. ${ }^{20}$ This p62 is usually degraded by the process of autophagy. ${ }^{21}$ This increased of p62 in psoriatic skin in comparison to control indicates a negative correlation between keratinocyte autophagy and p62 expression ${ }^{22}$ as p62 accumulation is considered an indicator for autophagy inhibition. ${ }^{23}$

In contrast, a recent study showed increased expression of $\mathrm{LC} 3(\mathrm{LC} 3 \mathrm{~A} / \mathrm{B}, \mathrm{LC} 3 \mathrm{~A}, \mathrm{LC} 3 \mathrm{~B})$ in psoriatic skin compared to control in a study included an equal number of patients and control (12 for each). This LC3 increased expression was associated with increase expression of BECN1 and ATG5, suggesting that autophagy is activated in psoriatic keratinocytes. ${ }^{24}$ The difference in our findings from the aforementioned could be attributed to different antibodies used. LC3B was used in the current study, while $\mathrm{LC} 3 \mathrm{~A} / \mathrm{B}, \mathrm{LC} 3 \mathrm{~A}, \mathrm{LC} 3 \mathrm{~B}$ were used in the other study. Also, the small sample size of the other study should be considered.

In the current study, the perilesional skin of psoriasis patients showed a significant reduction in LC3 expression 
compared with healthy skin; however, it was still higher than its expression in the lesional skin of psoriasis patients. This is consistent with previous findings. ${ }^{9}$ This could reflect the early changes that occur in the normalappearing skin around the psoriatic plaques. LC3 reduction could be due to the early inflammatory changes that occur in the perilesional skin. ${ }^{25}$

Autophagy is a self-eating machinery system that is responsible for the degradation of old and damaged intracellular materials. ${ }^{26}$ It plays a critical role in normal keratinocyte differentiation and melanocyte survival. ${ }^{18}$ The relationship between autophagy and inflammation is quite complex. The autophagy has a stimulant impact on the development and survival of inflammatory cells, ${ }^{27}$ however, autophagy could be injurious to the tissues if inflammation is not properly controlled. ${ }^{28}$

Autophagy could have a contributing role in psoriasis pathogenesis. Many pathogens have been linked to psoriasis including bacteria and viruses. ${ }^{29}$ In the same context, autophagy has an important role in eliminating these pathogens. So autophagy dysfunction could potentiate the action of these pathogens as a triggering factor for psoriasis development. ${ }^{30}$ A polymorphism in the Atg16L1 gene has been linked to psoriasis development which is essential for the autophagy pathway. ${ }^{10}$ This Atg16L1 gene product has a vital role in dealing with bacterial pathogens and antigen presentation, which could be responsible for psoriasis triggering. ${ }^{6}$ Therefore, autophagy dysfunction not only triggering psoriasis but also its inhibition could be responsible for aggravating the inflammatory process involved in psoriasis pathogenesis. ${ }^{20}$

In the current study, LC3 expression was significantly increased in the skin of control without MetS than the skin of control with MetS, suggesting that the presence of MetS could suppress autophagy in normal skin. However, there was no significant variation in LC3 expression in the lesional skin of psoriasis patients with/without MetS. No previous reports explore the relationship between MetS and autophagy in psoriasis vulgaris patients. Abnormal autophagy regulation in the skin could predispose to MetS development and vice versa. ${ }^{31}$ MetS could have different actions on different tissues as regards autophagy including autophagy reduction in liver tissue and activation in adipose tissue in patients with MetS. ${ }^{19}$ Autophagy dysfunction could contribute to the development of metabolic disorders and restoration of its function could have therapeutic benefits. ${ }^{5}$
In the current study, LC3 expression did not change with the severity of psoriasis as assessed by PASI score. There was no significant difference in LC3 expression compared to mild and moderate to severe patients. There are no previous reports about the relation between LC3 expression and the severity of psoriasis. This could be partially due to the non-significant difference in CRP comparing psoriasis patients and control although being higher in psoriasis patients. This could reflect the relatively low inflammatory mediators in the patients of the current study. Skin inflammation in psoriasis patients is usually accompanied by systemic inflammation and progressively increased with increasing psoriasis severity. ${ }^{32}$ CRP might be considered a good indicator of psoriasis severity and showed a significant decrease with treatment. ${ }^{33}$

There are several limitations of our study; the study sample had a relatively small size. Autophagy activity assessment was done with the use of only one marker (LC3). Therefore, future studies with larger sample size may be needed. It will be better to use more tools in autophagy assessment like transmission electron microscopy for the auto-phagosome demonstration which is the gold standard for autophagy monitoring. We could also use other autophagy markers with IHC like Beclin 1, p62/SQSTM1. It will be also of value to correlate the autophagy assessment and degree of $\mathrm{T}$ cell infiltration and the level of oxidative stress in psoriasis patients. A better understanding of these relationships may lead to the development of novel targets for therapeutic purposes.

\section{Conclusions}

There could be a potential link between psoriasis vulgaris and autophagy marker LC3 with lower skin expression in patients than in control. However, its expression did not change with severity or MetS. Autophagy enhancer might be used as a possible therapeutic target.

\section{Data Sharing Statement}

The datasets generated during and/or analyzed during the current study are available from the corresponding author on reasonable request.

\section{Ethics Approval}

The clinical trial was approved by the ethical and scientific research committee of Sohag University, Sohag, Egypt.

\section{Consent to Participate}

A written informed consent was obtained from all participants for the clinical study participation. 


\section{Author Contributions}

All authors contributed to data analysis, drafting or revising the article, have agreed on the journal to which the article will be submitted, gave final approval of the version to be published, and agree to be accountable for all aspects of the work.

\section{Funding}

The research is self-funded.

\section{Disclosure}

The authors report no conflicts of interest for this work.

\section{References}

1. Reali E, Brembilla NC. Editorial: immunology of psoriatic disease. Editorial. Front Immunol. 2019;10(657). doi:10.3389/ fimmu.2019.00657

2. Albanesi C. Immunology of psoriasis. Clin Immunol. 2019:871-878. e1. Elsevier.

3. Kothiwala SK, Khanna N, Tandon N, et al. Prevalence of metabolic syndrome and cardiovascular changes in patients with chronic plaque psoriasis and their correlation with disease severity: a hospital-based cross-sectional study. Indian J Dermatol Venereol Leprol. 2016;82 (5):510-518. doi:10.4103/0378-6323.183638

4. Milčić D, Janković S, Vesić S, et al. Prevalence of metabolic syndrome in patients with psoriasis: a hospital-based cross-sectional study. An Bras Dermatol. 2017;92(1):46-51.

5. Ryter SW, Koo JK, Choi AM. Molecular regulation of autophagy and its implications for metabolic diseases. Curr Opin Clin Nutr Metab Care. 2014;17(4):329-337. doi:10.1097/mco.0000000000000068

6. Yu T, Zuber J, Li J. Targeting autophagy in skin diseases. J Mol Med. 2015;93(1):31-38. doi:10.1007/s00109-014-1225-3

7. Kuma A, Matsui M, Mizushima N. LC3, an autophagosome marker, can be incorporated into protein aggregates independent of autophagy: caution in the interpretation of LC3 localization. Autophagy. 2007;3(4):323-328. doi:10.4161/auto.4012

8. Haruna K, Suga Y, Muramatsu S, et al. Differentiation-specific expression and localization of an autophagosomal marker protein (LC3) in human epidermal keratinocytes. J Dermatol Sci. 2008;52 (3):213-215. doi:10.1016/j.jdermsci.2008.07.005

9. Akinduro O, Sully K, Patel A, et al. Constitutive autophagy and nucleophagy during epidermal differentiation. $J$ Investig Dermatol. 2016;136(7):1460-1470. doi:10.1016/j.jid.2016.03.016

10. Douroudis K, Kingo K, Traks T, et al. Polymorphisms in the ATG16L1 gene are associated with psoriasis vulgaris. Acta Derm Venereol. 2012;92(1):85-87. doi:10.2340/00015555-1183

11. Wang J, Thornton JC, Bari S, et al. Comparisons of waist circumferences measured at 4 sites. Am J Clin Nutr. 2003;77(2):379-384. doi:10.1093/ajen/77.2.379

12. Fredriksson T, Pettersson U. Severe psoriasis-oral therapy with a new retinoid. Clinical trial randomized controlled trial. Dermatologica. 1978;157(4):238-244. doi:10.1159/000250839

13. Mrowietz U, Kragballe K, Reich K, et al. Definition of treatment goals for moderate to severe psoriasis: a European consensus. Consensus development conference research support, non-US Gov't. Arch Dermatol Res. 2011;303(1):1-10. doi:10.1007/s00403010-1080-1

14. Kassi E, Pervanidou P, Kaltsas G, Chrousos G. Metabolic syndrome: definitions and controversies. BMC Med. 2011;9:48. doi:10.1186/ 1741-7015-9-48
15. Assaad-Khalil SH, Mikhail MM, Aati TA, et al. Optimal waist circumference cutoff points for the determination of abdominal obesity and detection of cardiovascular risk factors among adult Egyptian population. Indian J Endocrinol Metab. 2015;19(6):804. doi:10.4103/2230-8210.167556

16. Zhang L, Zhang J, Chen L, Wang J. Autophagy in human skin squamous cell carcinoma: inhibition by 3-MA enhances the effect of 5-FU-induced chemotherapy sensitivity. Oncol Rep. 2015;34 (6):3147-3155. doi:10.3892/or.2015.4302

17. Gisondi P, Bellinato F, Girolomoni G, Albanesi C. Pathogenesis of Chronic Plaque Psoriasis And Its Intersection With Cardio-Metabolic Comorbidities. Front Pharmacol. 2020;11:117. doi:10.3389/ fphar.2020.00117

18. Nagar R. Autophagy: a brief overview in perspective of dermatology. Review. Indian J Dermatol Venereol Leprol. 2017;83(3):290-297. doi:10.4103/0378-6323.196320

19. Menikdiwela KR, Ramalingam L, Rasha F, et al. Autophagy in metabolic syndrome: breaking the wheel by targeting the renin-angiotensin system. Review. Cell Death Dis. 2020;11 (2):020-2275.

20. Varshney P, Saini N. PI3K/AKT/mTOR activation and autophagy inhibition plays a key role in increased cholesterol during IL-17A mediated inflammatory response in psoriasis. Research support, nonUS gov't. Biochim Biophys Acta Mol Basis Dis. 2018;5(10):9.

21. Pankiv S, Clausen TH, Lamark T, et al. p62/SQSTM1 binds directly to Atg8/LC3 to facilitate degradation of ubiquitinated protein aggregates by autophagy. J Biol Chem. 2007;282(33):24131-24145. doi:10.1074/jbc.M702824200

22. Lee HM, Shin DM, Yuk JM, et al. Autophagy negatively regulates keratinocyte inflammatory responses via scaffolding protein p62/ SQSTM1. J Immunol. 2011;186(2):1248-1258. doi:10.4049/ jimmunol.1001954

23. Nakai A, Yamaguchi O, Takeda T, et al. The role of autophagy in cardiomyocytes in the basal state and in response to hemodynamic stress. Nat Med. 2007;13(5):619-624. doi:10.1038/nm1574

24. Wang Z, Zhou H, Zheng H, Zhou X. Autophagy-based unconventional secretion of HMGB1 by keratinocytes plays a pivotal role in psoriatic skin in fl ammation. Autophagy. 2020;1-24. doi:10.1080/ 15548627.2020 .1725381

25. Komine M, Karakawa M, Takekoshi T, et al. Early inflammatory changes in the "perilesional skin" of psoriatic plaques: is there interaction between dendritic cells and keratinocytes? J Invest Dermatol. 2007;127(8):1915-1922. doi:10.1038/sj.jid.5700799

26. Pesonen M, Vähäkangas K. Autophagy in exposure to environmental chemicals. Toxicol Lett. 2019;305:1-9. doi:10.1016/j. toxlet.2019.01.007

27. Qian M, Fang X, Wang X. Autophagy and inflammation. Clin Transl Med. 2017;6(1):24. doi:10.1186/s40169-017-0154-5

28. Netea-Maier RT, Plantinga TS, van de Veerdonk FL, Smit JW, Netea MG. Modulation of inflammation by autophagy: consequences for human disease. Autophagy. 2016;12(2):245-260. doi:10.1080/ 15548627.2015.1071759

29. Campalani E, Barker JNWN. The clinical genetics of psoriasis. Curr Genomics. 2005;6(1):51-60. doi:10.2174/1389202053202157

30. Guo Y, Zhang X, Wu T, Hu X, Su J, Chen X. Autophagy in skin diseases. Review. Dermatology. 2019;235(5):380-389. doi:10.1159/ 000500470

31. Zhou SS, Li D, Zhou YM, Cao JM. The skin function: a factor of anti-metabolic syndrome. Diabetol Metab Syndr. 2012;4(1):15. doi:10.1186/1758-5996-4-15

32. Gokalp H. Effect of psoriasis severity on inflammation parameters: controlled study. Turk J Dermatol. 2018;52. doi:10.4274/ turkderm.05025.

33. Beygi S, Lajevardi V, Abedini R. C-reactive protein in psoriasis: a review of the literature. J Eur Acad Dermatol Venereol. 2013;28. doi:10.1111/jdv.12257. 


\section{Publish your work in this journal}

Clinical, Cosmetic and Investigational Dermatology is an international, peer-reviewed, open access, online journal that focuses on the latest clinical and experimental research in all aspects of skin disease and cosmetic interventions. This journal is indexed on CAS.

The manuscript management system is completely online and includes a very quick and fair peer-review system, which is all easy to use. Visit http://www.dovepress.com/testimonials.php to read real quotes from published authors.

Submit your manuscript here: https://www.dovepress.com/clinical-cosmetic-and-investigational-dermatology-journal 